\title{
CROMOMICOSE POR FONSECAEA PEDROSOI APRESENTANDO AS TRES FASES CONI- DIAIS, ACROGENA, ACROPLEUROGENA E SEMI-ENDOGENA
}

A.M. LACERDA F., M.J.S. FERNANDES \& L.A. QUEIROZ.

Departamento de Micología do Centro de Ciências Biológicas da Universidade Federal de Pernambuco. Av. Prof. Artur de Sá s/n, Recife 50.000, Brasil.

\section{RESUMO}

Uma amostra de Fonsecaea pedrosoi (Brumpt) Negroni 1936, isolada de um caso de cromomicose forma plana, apresentou as três fases de esporulafâo: tipo Cladosporium, tipo Rhinocladiella e tipo Phialophora.

\section{RESUMEN}

[ Cromomicosis por Fonsecaea pedrosoi, presentando tres fases conidiales, acrógena, acropleurogena y semiendógena ]

Una muestra de Fonsecaea pedrosoi (Brumpt) Negroni 1936, fue aislada de un caso de cromomicosis forma plana y presentó tres fases de esporulación: Cladosporium, Rhinocladiella y Phialophora.

\section{INTRODUCAO}

A cromomicose caracteriza-se particularmente pela formaçâo de nódulos cutâneos verrucosos formados no decurso de sua evoluçâo $(1,4,5)$; entre as diferentes formas clínicas, tem sido descrita uma forma plana, tricofitóide, papulosa nos bordos e com cicatrizaçâo central (5). A etiologia está associada a fungos dematiáceos e entre estes Fonsecaea pedrosoi (Brumpt) Negroni 1936 (1, $4,5,6)$ ao qual estâo relacionadas três fases conidiais: acrógena tipo Cladosporium, acropleurógena tipo Rhinocladiella e semi-endógena tipo Phialophora; estes sâo encontrados em proporçôes variáveis dependendo das amostras e do meio de cultura; os tipos Cladosporium $\mathrm{e}$ Rhinocladiella podem estar presentes em proporçôes equivaléntes ou predominando um sobre o outro; o tipo Phialophora geralmente é escasso ou ausente $(1,5,6)$; algumas amostras entretanto podem apresentar os três tipos de frutificaçâo (5). Tém sido descritos corpos semelhantes a esclerócios e a cleistotécios $(1,3,6)$. Ao exame direto sâo observados corpos fumagóides ou células escleróticas que sâo estruturas escuras e esféricas com tabiques; algumas vezes podem ser encontrados filamentos pardos, ramificados e septados (1, 2, $3,4,5,6)$.

\section{SUMMARY}

[ Chromomycosis due to Fonsecaea pedrosoi presenting three conidial stages: Acrogenous, acropleurogenous and semi-endogenous. ]

A strain of Fonsecaea pedrosoi (Brumpt) Negroni 1936, was isolated from a cromomycosis plain form case and it presented the characteristic three types of sporulation: Cladospodium, Rhinocladiella and Phialophora.

\section{MATERIAL E METODO}

Escamas e crostas foram colectadas de uma lesâo de cromomicose forma plana com 10 anos de evoluçâo, localizada no antebraço esquerdo (Fig. 1) de um agricultor com 70 anos de idade. Para exame direto, parte do material foi clarificado com soluçâo aquosa de hidróxido de potássio $(\mathrm{KOH})$ a $30 \%$. Do material semeado em Sabouraud-cloranfenicol e deixado a temperatura ambiente (T.A.) oscilante entre $25^{\circ} \mathrm{C}$ e $30^{\circ} \mathrm{C}$, resultou o isolamento de um fungo, o qual foi repicado em ágar Sabouraud (AS) e ágar batata dextrose (ABD) e mantido à T.A. para posterior observaçâo macro e microscópica. A cor das colônias foi determinada atraves da Saccardo's Chromotaxia (7).

\section{RESULTADOS E DISCUSSAO}

O exame direto revelou a presença de corpos fumagôides isolados, agrupados e com tabiques (Fig. 2) assim como fragmentos de hifas escuras e septadas (Fig. 3). As colônias desenvolvidas atè 20 dias, apresentaram aspecto aveludado nos dois meios de cultura usados; em AS a cor do verso 
variou de 35 Viridis a 5 Niger e em ABD de 34 Atrovirens a 11 Fuligineus; em ambos meios o reverso apresentou-se concolor com o verso.

Nas culturas desenvolvidas em AS e ABD a microscopia revelou a presença conjunta das três fases conidiais acrógena tipo Cladosporium (Fig. 4), acropieurógena tipo Rhinocladiella (Fig. 5) e semiendógena tipo Phialophora (Fig. 6), assim como estruturas escuras semelhantes a cleistotécios (Fig. 7). Pelos resultados o fungo isolado foi identificado como Fonsecaea pedrosoi (Brumpt) Negroni 1936 e encontra-se depositado na Micoteca URM sob o $\mathrm{N}^{\mathrm{O}} 2806$.

Tem sido raramente mencionada a presença conjunta das três fases conidiais em uma mesma amostra de Fonsecaea pedrosoi.

\section{REFERENCIAS}

1. CONANT, N.F., SMITH, D.T., BAKER, R.D. \& CALLAWAY, J.L. (1971). Manual of clinical mycology, 3. ed. Philadelphia \& London, Sauders, 755 p.

2. HARADA, S. \& KUSONOKI, T. (1983). Scanning electron microscopic observation of the parasitic forms of Fonsecaea pedrosi in human skin lesion. Mycopath. 82: 33-7.

3. IBRAHIM-GRANET, O. \& BIEVRE, C. (1984). Study of the Conidial development and cleistothecium-like structure of some strains of Fonsecaea pedrosoi. Mycopath. 84: 181-6.
4. LACAZ, C.L. (1973). Compêndio de micologia médica. 5.ed. Sâo Paulo, Editora Sarvier \& Instituto Nacional do Livro/MEC, 502 p.

5. NEGRONI, P. \& NEGRONI, R. (1984). Micosis cutaneas y viscerales. 8.ed. Buenos Aires, Lopez Libreros Editores S.R.L., 240 p.

6. RIPPON, J.W. (1982) Medical mycology. The pathogenic fungi and the pathogenic actinomyces. 2.ed. Philadelphia, Saunders Company, $842 \mathrm{p}$.

7. SACARDO. P.A. (1894). Saccardo's chromotaxia. 2.ed. Padua. (s.p.). 
1

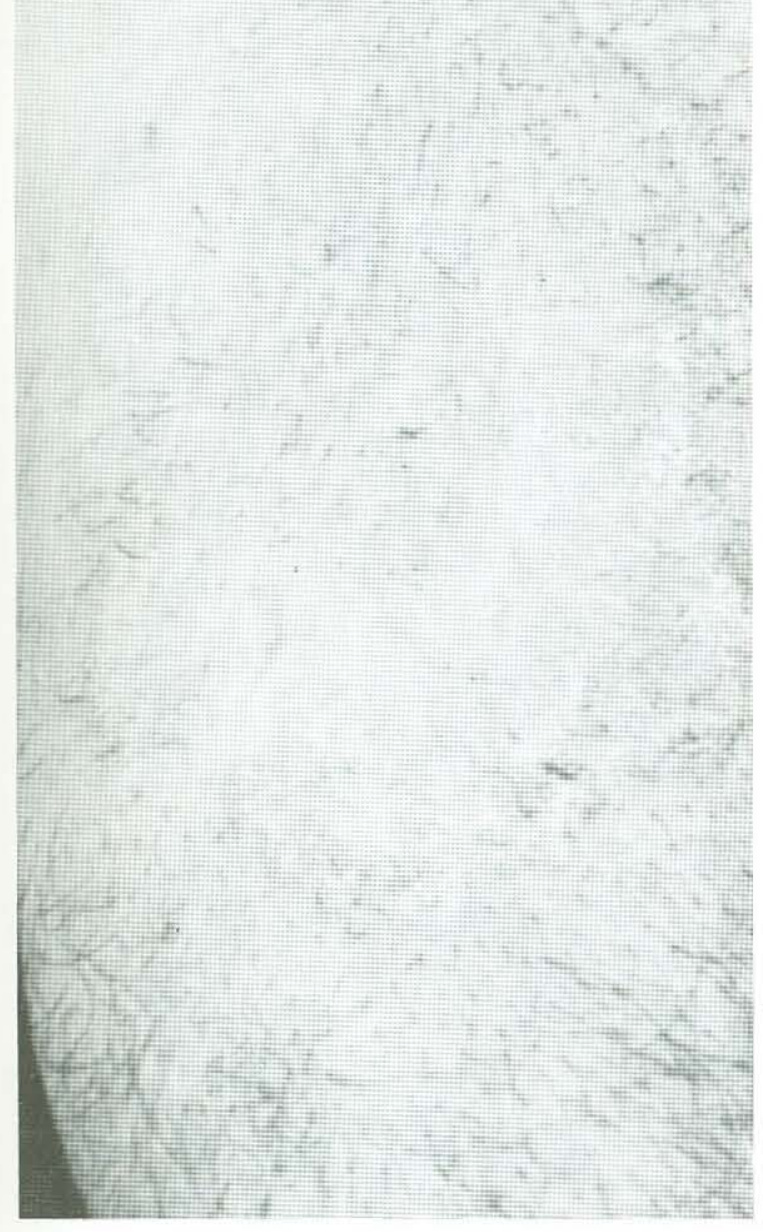

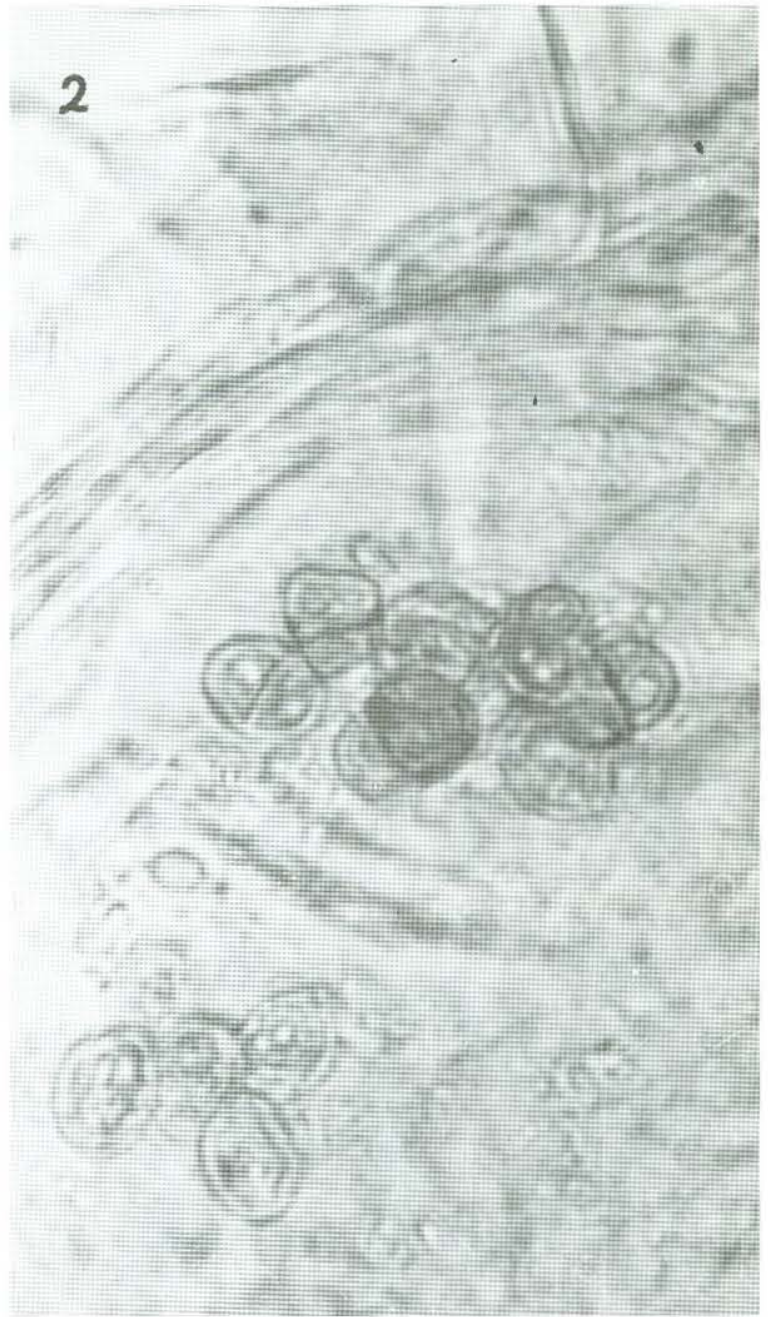

3 todit?

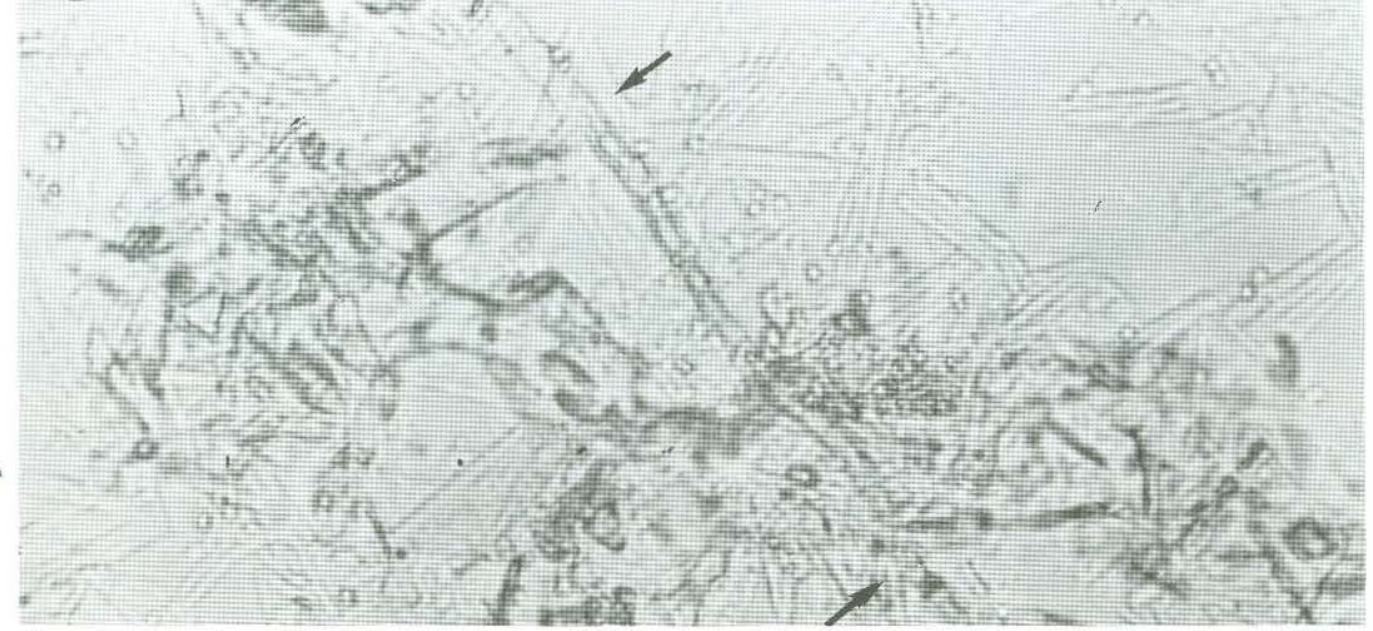



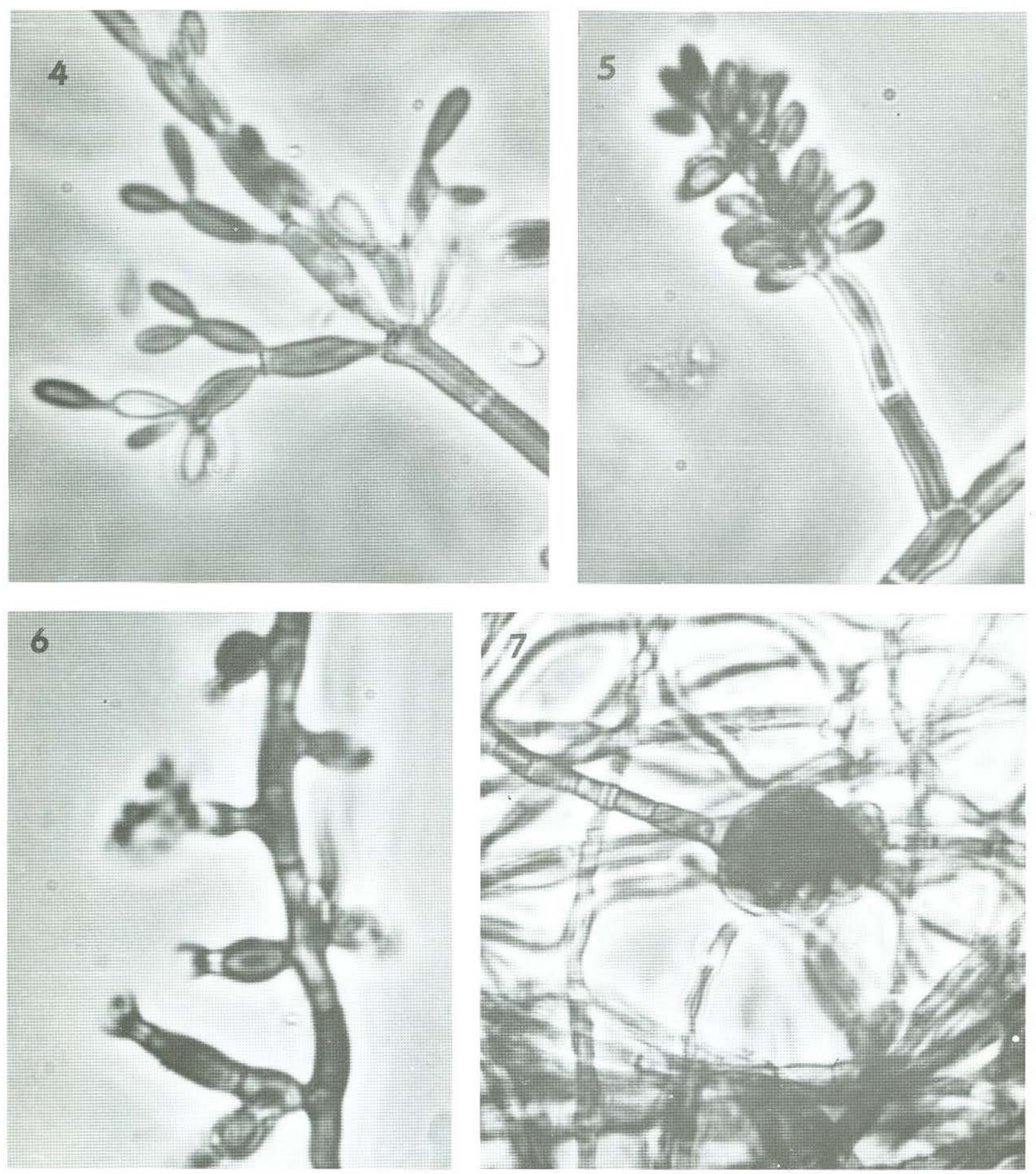

Fig. 1 - Lesâo de cromomicose forma plana no antebraço esquerdo. Fig. 2 - Corpos fumagôides. Fig. 3 - Fragmento de hifa $\downarrow$ Fig. 4 -'Fases conidiais: tipo Cladosporium. Fig. 5 - tipo Rhinocladiella. Fig. $6-$ tipo Phialaphora. Fig. 7 - Estrurura escura semelhante a cleistotécio. 